\title{
Oral Contraceptive Intake and lodine Status in Young Women
}

\author{
Carola Deischinger $^{\mathrm{a}}$ Doris Deischinger ${ }^{\mathrm{a}} \quad$ |rina Gess| $^{\mathrm{b}}$ Michael Krebs $^{\mathrm{a}}$ \\ Rodrig Marculescu ${ }^{c}$ Alexandra Kautzky-Willer ${ }^{a}$ Lana Kosi-Trebotic ${ }^{a}$
}

${ }^{a}$ Clinical Division of Endocrinology and Metabolism, Department of Medicine III, Medical University of Vienna, Unit of Gender Medicine, Vienna, Austria; ${ }^{b}$ Clinical Division of Rheumatology, Department of Medicine III, Medical University of Vienna, Vienna, Austria; 'Clinical Institute for Medical and Chemical Laboratory Diagnostics, Department of Laboratory Medicine, Medical University of Vienna, Vienna, Austria

\section{Keywords}

lodine - Urinary iodine concentration - Women - Oral

contraceptive $\cdot$ lodine deficiency

\section{Abstract}

Objective: Similar to pregnant women, women taking an oral contraceptive $(\mathrm{OC})$ might have elevated iodine requirements due to the altered hormonal state. This is the first study aimed at investigating the prevalence of iodine deficiency and possible influences of $\mathrm{OC}$ intake on urine creatinine and iodine levels in young women. Methods: One hundred fifty-five women between the age of 18 and 35 years (62 taking an OC and 93 controls) participated in a crosssectional pilot study at the Medical University of Vienna, which included a 1-spot urine sample and a questionnaire on OC intake as well as a food questionnaire. Results: The median urinary iodine concentration (UIC) in this study was $68 \mu \mathrm{g} / \mathrm{L}(41,111 \mu \mathrm{g} / \mathrm{L})$ suggesting an inadequate iodine status in the women according to the WHO guidelines. Median UIC (OC: $89 \mu \mathrm{g} / \mathrm{L}$, IQR 55-120; control: $59 \mu \mathrm{g} / \mathrm{L}$, IQR 39-91, $p$ $=0.010$ ) and urine creatinine (OC: median $=99.0 \mu \mathrm{g} / \mathrm{L}$, IQR

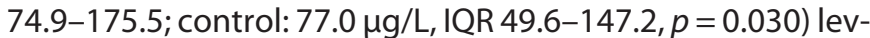

karger@karger.com www.karger.com/anm

Karger!"
(C) 2021 The Author(s)

Published by S. Karger AG, Base

This article is licensed under the Creative Commons Attribution 4.0 International License (CC BY) (http://www.karger.com/Services/ OpenAccessLicense). Usage, derivative works and distribution are permitted provided that proper credit is given to the author and the original publisher. els were significantly higher in $\mathrm{OC}$ women than in the control group. UIC corrected for urine creatinine was comparable between both groups. Conclusion: With similar creatininecorrected UICs in both groups, OC intake might not have a significant impact on iodine status. However, the low median UIC in a vulnerable group of young women potentially conceiving in the following years points at the necessity of optimizing the iodine intake in the Austrian population and reiterates the insufficiency of the current iodine supplementation measures.

(C) 2021 The Author(s)

Published by S. Karger AG, Basel

\section{Introduction}

Iodine is a critically important nutrient well known for its role in thyroid health [1]. However, almost a third of all countries worldwide are still considered iodine deficient [2]. This is of utmost importance in pre-gestation and gestation due to its effects on neurodevelopment and fecundability $[3,4]$. The relevance of adequate iodine supply during pregnancy is especially evident due to its influence on the neurodevelopment of the unborn child 
$[5,6]$, which begins in the third to fourth week of gestation and may be affected by the mother's thyroid and pregestational iodine status $[3,7]$. It is therefore essential to identify potential mediators of the iodine status in women at child-bearing age.

In Austria, according to a previously conducted study by Lindorfer et al. [8], $82.2 \%$ of all included pregnant Austrian women had an iodine deficiency varying from slight to severe. Pregnant women are more susceptible to iodine deficiency due to a $50 \%$ increased thyroid hormone synthesis, passage of iodine through the placenta to aid in fetal thyroid hormone production, and $30-50 \%$ higher renal iodide loss due to progressively increasing glomerular filtration rate (GFR) and renal plasma flow [1, 3, 9-12]. Oral contraceptives (OCs), the most frequent form of contraception, are also known to increase GFR $[13,14]$, which could result in increased renal iodine loss as well. Possible explanations for the higher GFR while on OC include a vasodilatative effect of the estrogen component [15] and progesterone causing natriuresis, potentially predisposing to a loss of iodine [10]. Furthermore, iodine is an essential component in thyroid hormone production [11]. According to the free thyroid hormone hypothesis, thyroxine-binding globulin (TBG) concentrations rise when excess estrogen is present [11]. Accordingly, pregnant women and women using birth control pills have similarly high total and free TBG binding capacity due to more thyroxine (T4) being bound to TBG [16]. An increased TBG concentration leads to a free T4 reduction and a compensatory increase in thyroid hormone production for which iodine is needed [11].

As data on the possible role of estrogen and progesterone on thyroid and iodine levels are still insufficient [17, 18], women using OC might be at risk of developing iodine deficiency. Therefore, we aimed at investigating the iodine status (urinary iodine concentration - UIC; creatinine-corrected UIC) of Austrian women from the age of 18 to 35 and OC as a potential influence.

\section{Study Design and Methods}

This cross-sectional pilot study is the analysis of UIC, creatinine levels, and creatinine-corrected UIC in 155 (61 in the OC group and 93 in the control group) nulliparous, Caucasian, female students at the Medical University of Vienna between December 2016 and December 2019. The women were currently either taking a combination OC or had not been taking a form of OC within 6 months before the participation (control group). Women in the OC group ought to have taken an $\mathrm{OC}$ for at least 3 months prior to the submission of the urine sample. Primary outcomes are UIC and creatinine-corrected UIC to establish the iodine status of the participating women. The participants submitted a morning spot urine sample ( $10 \mathrm{~mL}$ per person, after at least an 8 -h fast) and completed a questionnaire on their contraceptive pill intake (duration, type of OC, and brand), 24-h recall of foods containing high amounts of iodine, height, weight, and smoking status. The 24-h diet recall included questions on milk, cheese, yoghurt, seafood, and fish consumption due to their high iodine content [19]. None of the women had consumed seafood within the past $24 \mathrm{~h}$. Therefore, seafood consumption was excluded from all further analyses. Exclusion criteria were exposure to iodinated contrast media, an iodine-containing disinfecting agent in the last 6 weeks, amiodarone within the past 24 months, pregnant or breastfeeding in the last 6 months, hyperthyroidism within the past 12 months, and progestin-only birth control pills or any other nonoral contraceptives. Individuals with diagnosed liver problems or renal insufficiency were excluded as well because UIC might not correctly reflect iodine status. Of 185 screened women, 30 were excluded, leaving 155 women for the analysis. Women were predominantly excluded due to the intake of progestin-only birth control or the use of nonoral contraceptives, which resulted in a higher number of women in the control group (93) than in the OC group (62). In the urine analysis, creatinine levels in milligrams per deciliter and iodine levels in micrograms per liter via a microphotometric method (Sandell-Kolthoff method) were measured. All samples were analyzed in our ISO 9001-certified central laboratory at the General Hospital in Vienna (AKH Wien). Methods are available under the homepage of the institute of laboratory medicine, www.kimcl. at. Creatinine-corrected iodine levels were calculated using the measured creatinine and iodine levels.

\section{Statistical Methods}

Normal distribution was checked via the calculation of skewness using the Kolmogorov-Smirnov test. Nonparametric data were described as median and interquartile range (IQR), normally distributed data as mean and standard deviation, and categorical baseline characteristics as percentages and frequencies. Potential differences in normally distributed baseline characteristics such as weight, height, and age were assessed with independent samples $t$ tests. To compare the nonparametric variables iodine, creatinine, milk, cheese, yoghurt, seafood, and fish consumption between the $\mathrm{OC}$ and the control group, each of these variables was log10 transformed, and a $t$ test and an ANCOVA correcting for smoking status, BMI, age, milk, cheese, yoghurt, and sea fish consumption were performed. A linear regression was calculated to evaluate potential influencing factors of creatinine-corrected iodine. The collected data were analyzed with SPSS (Version 25).

\section{Results}

As presented in Table 1, baseline characteristics such as age, height, weight, and smoking behavior were not significantly different between the 2 groups. Concerning the 24 -h recall on iodine-containing foods, the consumption of iodine-rich foods was similar in the OC and the control group (see Table 1). The mean time on OC was 62 months ( \pm 39$)$, ranging from 3 to 156 months. 
Table 1. Baseline characteristics of women taking OC and controls

\begin{tabular}{|c|c|c|c|c|}
\hline \multirow[t]{2}{*}{ Baseline characteristics } & \multicolumn{2}{|c|}{$\mathrm{OC}(N=62)$} & \multicolumn{2}{|c|}{ Control group $(N=93)$} \\
\hline & mean & SD & mean & SD \\
\hline Age, years & 26.2 & 12.3 & 26.9 & 5.2 \\
\hline Height, cm & 168 & 6 & 168 & 7 \\
\hline Weight, kg & 61.1 & 8.4 & 61.8 & 10.3 \\
\hline Duration of OC intake, months & 62 & 39 & & \\
\hline Estrogen content of OC, mg & 1.11 & 1.12 & & \\
\hline Progesterone content of $\mathrm{OC}, \mathrm{mg}$ & 0.05 & 0.19 & & \\
\hline \multicolumn{5}{|l|}{ Food and lifestyle questionnaire } \\
\hline Milk consumption, $\mathrm{mL}$ & 103 & 126 & 133 & 187 \\
\hline Cheese consumption, g & 32 & 37 & 34 & 40 \\
\hline Yoghurt, g & 50 & 93 & 67 & 118 \\
\hline Sea fish, $g$ & 20 & 68 & 48 & 108 \\
\hline \multirow[t]{2}{*}{ Smoking prevalence, $\%$} & $14.5(9 / 62$ & \multicolumn{3}{|c|}{$15.1(14 / 93)$} \\
\hline & median & IQR & median & IQR \\
\hline \multicolumn{5}{|l|}{ Urine spot analysis } \\
\hline $\mathrm{UIC}, \mu \mathrm{g} / \mathrm{L}$ & $89^{* *}$ & $55-120$ & $59^{* *}$ & 39-91 \\
\hline Urine creatinine, $\mathrm{mg} / \mathrm{dL}$ & $99.0^{*}$ & $74.9-175.5$ & $77.0^{*}$ & $49.6-147.2$ \\
\hline Creatinine-corrected iodine, $\mathrm{g} / \mathrm{gCr}$ & 74 & $52-120$ & 74 & 49-147 \\
\hline \multicolumn{5}{|c|}{$\begin{array}{l}\text { Continuous variables were summarized by mean } \pm \text { standard deviation and median and interquartile range } \\
\text { and categorical variables by percentages. To assess differences between women on birth control and the control } \\
\text { group, an independent samples } t \text { test was performed. OC, oral contraceptive; UIC, urinary iodine concentration. } \\
{ }^{*} \text { The significance level is } p<0.05 \text {. } * \text { The significance level is } p<0.01 \text {. }\end{array}$} \\
\hline
\end{tabular}

In the $t$ test, UIC $(p=0.010)$ and urine creatinine $p=$ 0.030 ) were significantly higher in women on an OC than in the control group. However, in an ANCOVA corrected for smoking status, BMI, age, milk, cheese, yoghurt, and sea fish intake, the creatinine-corrected iodine did not differ between the groups (mean difference $=0.035, p=0.506$ ).

A linear regression model investigating creatininecorrected iodine ( $\left.p=0.286, R^{2}=0.014\right)$ showed no relevant impact of smoking status $(\beta=-0.001, p=0.497)$, $\operatorname{BMI}(\beta=-0.066, p=0.207)$, age $(\beta=0.022, p=0.394)$, cheese intake $(\beta=0.098, p=0.112)$, sea fish intake $(\beta=$ $0.033, p=0.343)$, duration of OC intake $(\beta=-0.030, p=$ $0.356)$, and estrogen $(\beta=-0.003, p=0.483) /$ progesterone $(\beta=0.067, p=0.203)$ content of the OC. Only milk $(\beta=$ $0.160, p=0.023)$ and yoghurt consumption $(\beta=0.164$, $p=0.021)$ had a significant impact on creatinine-corrected iodine levels. According to the WHO guidelines [20], which defines an inadequate iodine status as a median UIC below $100 \mu \mathrm{g} / \mathrm{L}$, the median (IQR) UIC of $89 \mu \mathrm{g} / \mathrm{L}$ $(55,120 \mu \mathrm{g} / \mathrm{L})$ in the OC group, $59 \mu \mathrm{g} / \mathrm{L}(39,91 \mu \mathrm{g} / \mathrm{L})$ in the control group, and a median UIC of $68 \mu \mathrm{g} / \mathrm{L}$ (41, $111 \mu \mathrm{g} / \mathrm{L})$ in the whole population indicate an inadequate iodine status in the participating women.

Oral Contraceptive Intake and Iodine Status

\section{Discussion}

To the best of our knowledge, no previous study on this topic has been published. Contrary to what was hypothesized, women who were taking an OC did not display less advantageous iodine statuses than the control group. Median UIC was higher in the OC group while creatinine-corrected UIC did not display differences between the 2 groups in this study. Creatinine-corrected UIC is considered a more reliable measure of iodine excretion as it allows to take variability in hydration level, muscle mass, and physical activity into account [21]. The higher levels of urine creatinine and iodine excretion in women who were taking an OC might be explained by the association of OC intake with a higher GFR [13]. The vasodilatative effect of estrogen increases GFR; the natriuretic effect of synthetic progesterone predisposes to a renal loss of iodine $[13,15]$. Since the spironolactone-derivative drospirenone is similar to progesterone, drospirenone-containing oral contraceptives might exert a similar effect and lead to an increased urine iodine excretion. In pregnancy, women have a higher UIC/increased renal iodine loss [22], which the adjusted thresholds in preg- 
nant women take into account [20]. The same effect could apply to the women taking OCs in this study though and, therefore, potentially masking an iodine deficiency [21]. However, our analysis did not demonstrate any effect of estrogen and progesterone dosages on UIC or creatininecorrected UIC.

In the whole cohort, the median UIC of $68 \mu \mathrm{g} / \mathrm{L}(41$, $111 \mu \mathrm{g} / \mathrm{L}$ ) suggests an inadequate iodine status in the participating women according to the WHO guidelines [20]. In general, a one-time urine sample is not the gold standard for approximating the iodine status in an individual person due to its daily fluctuations and dependence on factors such as diet and water intake. When examining larger sample sizes, these variations are mostly expected to level out [23]. According to König et al. [24], another way of increasing the precision of our analysis would have been to use 10 spot urine samples per person. To improve the reliability of the spot urine samples in this study, we creatinine-corrected iodine levels to account for variability in hydration levels and collected information on high-iodine food intake in a 24-h diet recall. Except for milk and yoghurt consumption, which only exerted a negligible effect, none of the iodine-containing foods in our 24-h recalls were significantly related to UIC in our analysis, and there were no differences in milk, cheese, yoghurt, and sea fish intake between the OC and the control group. What we were not able to account for is voluntary salt reduction or the substitution of iodized salt with perceived "healthier" alternatives such as Himalayan salt, which might also have an influence on the proportion of low UIC indicating iodine deficiency in our population rather than insufficient salt fortification strategies.

Another lifestyle factor, namely, smoking, was accounted for in our analysis due to the antithyroid effect of thiocyanate in cigarettes [25]. Thiocyanate in cigarettes can act as an antithyroid agent by inhibiting iodide transport, iodine organification, and increasing iodide efflux [25]. Furthermore, smoking has been associated with goiter [26], an increased risk for autoimmune disorders of the thyroid gland [27] and lower thyrotropin (TSH) levels [28]. However, smoking status had no significant effect on UIC or creatinine-corrected UIC in this analysis.

A limitation of this study is that it is a small, 1-site pilot study, and there are significant differences in iodine levels between the east and west of Austria [29]. Therefore, the results of this study might not be transferable onto areas in the west. However, the homogeneity of the pool of study participants in other baseline characteristics such as age, weight, height, and smoking status is also one of the main strengths of this study. Information on thyroid status such as free tri-iodothyronine (fT3), free thyroxine (fT4), thyroid-stimulating hormone (TSH), and TBG would have been beneficial in this pilot study and should be incorporated in potential future investigations on this topic. Furthermore, potential follow-up studies would be advised to use at least 10 spot urine analyses per person to increase the reliability of the UIC measurements.

Considering the creatinine-corrected UIC was not significantly different between the 2 groups, the higher UIC in women taking OCs might be due to variability in factors such as water intake rather than depicting the actual iodine status. Although we were glad to see that OCs do not negatively affect women's iodine status, still the median UIC of the participating women suggests an inadequate iodine intake despite decades of salt iodization. Therefore, current strategies for salt fortification with iodine might be insufficient. Our results indicate a poor iodine status even in nonpregnant young women in Austria which makes this topic a highly relevant public health issue $[8,30]$. Considering the likelihood of young women between the age of 18 and 35 getting pregnant, achieving adequate preconception iodine levels in this subgroup is especially important for the future of our children and a sensible recommendation regardless of OC intake.

\section{Acknowledgment}

In memoriam of Prof. Dr. Alois Gessl, who originated this pilot study.

\section{Statement of Ethics}

The study was approved by the local ethics committee (Ethics Committee of the Medical University of Vienna, No. 1190/2016) and performed in accordance with the Declaration of Helsinki. All participants gave written informed consent for participation in the study.

\section{Conflict of Interest Statement}

All authors have no conflicts of interest to disclose.

\section{Funding Sources}

The authors have no funding to disclose. 


\section{Author Contributions}

C.D. wrote the manuscript and researched data. D.D., I.G., and A.G. researched data and contributed to the methods. R.M. contributed to the methods and reviewed the manuscript. M.K.,
L.K.-T., and A.K.-W. contributed to the discussion and reviewed/ edited the manuscript. L.K.-T. is the guarantor of this work and, as such, had full access to all the data in the study and takes responsibility for the integrity of the data and the accuracy of the data analysis.

\section{References}

1 Zimmermann MB. Iodine deficiency. Endocr Rev. 2009;30(4):376-408.

2 Taylor PN, Vaidya B. Iodine supplementation in pregnancy: is it time? Clin Endocrinol. 2016;85(1):10-4.

3 Harding KB, Peña-Rosas JP, Webster AC, Yap $\mathrm{CM}$, Payne BA, Ota E, et al. Iodine supplementation for women during the preconception, pregnancy and postpartum period. Cochrane Database Syst Rev. 2017;3:CD011761.

4 Mills JL, Buck Louis GM, Kannan K, Weck J, Wan Y, Maisog J, et al. Delayed conception in women with low-urinary iodine concentrations: a population-based prospective cohort study. Hum Reprod. 2018;33(3):426-33.

5 Bath SC, Steer CD, Golding J, Emmett P, Rayman MP. Effect of inadequate iodine status in uk pregnant women on cognitive outcomes in their children: results from the avon longitudinal study of parents and children (ALSPAC). Lancet. 2017;382(9889):331-7.

6 Hynes KL, Otahal P, Hay I, Burgess JR. Mild iodine deficiency during pregnancy is associated with reduced educational outcomes in the offspring: 9-year follow-up of the gestational iodine cohort. J Clin Endocrinol Metab. 2013;98(5):1954.

7 Bernal J. Thyroid hormone receptors in brain development and function. Nat Clin Pract Endocrinol Metab. 2007;3(3):249-59.

8 Lindorfer H, Krebs M, Kautzky-Willer A, Bancher-Todesca D, Sager M, Gessl A. Iodine deficiency in pregnant women in Austria. Eur J Clin Nutr. 2015;69:349.

9 Glinoer D. The importance of iodine nutrition during pregnancy. Public Health Nutr. 2007;10(12A):1542-6.

10 Cheung KL, Lafayette RA. Renal physiology of pregnancy. Adv Chronic Kidney Dis. 2014; 20(3):209-14.

11 Kronenberg HM, Melmed S, Polonsky KS, Reed Larsen P. Williams textbook of endocrinology. 11th ed. Philadelphia, PA: Elsevier Inc.; 2008.
12 Wiles K, Bramham K, Seed PT, Nelson-piercy C, Lightstone L, Chappell LC. Serum creatinine in pregnancy : a systematic review. Kidney Int Reports. 2019;4(3):408-19.

13 Brändle E, Gottwald E, Melzer H, Sieberth HG. Influence of oral contraceptive agents on kidney function and protein metabolism. Eur J Clin Pharmacol. 1992;43:643-6.

14 Pechere-Bertschi A, Maillard M, Stalder $\mathrm{H}$, Bischof P, Fathi M, Brunner HR, et al. Renal hemodynamic and tubular responses to salt in women using oral contraceptives. Kidney Int. 2003;64:1374-80

15 Mueck AO, Seeger H, Petersen G, Schultewintrop E. Effect of two oral contraceptives with different ethinyl estradiol and levonorgestrel concentrations on the urinary excretion of biochemical vasoactive markers. Contraception. 2002;64:357-62.

16 Cuaron A, Hoppee de Cuaron C. Tables to estimate total binding capacity of thyroxinebinding globulin from the in vitro thyroid function tests. J Nucl Med. 1979;20(1):67-71.

17 Quinkler M, Meyer B, Oelkers W, Diederich $S$. Renal inactivation, mineralocorticoid generation, and 11beta-hydroxysteroid dehydrogenase inhibition ameliorate the antimineralocorticoid effect of progesterone in vivo. J Clin Endocrinol Metab. 2003;88(8):3767-72.

18 Diedrich K, Holzgreve W, Jonat W, SchultzeMosgau A, Schneider KTM, Weiss JM, et al. Gynäkologie Und Geburtshilfe, 2. Auflage. Heidelberg: Jürgen M. Weiss; 2007.

19 Pearce EN, Andersson M, Zimmermann MB. Global iodine nutrition: where do we stand in 2013? Thyroid. 2013;23(5):523.

$20 \mathrm{WHO} / \mathrm{ICCIDD} / \mathrm{UNICEF}$. Assessment of iodine deficiency disorders and monitoring their elimination a guide for programme managers. 3rd ed. Geneva, Switzerland: World Health Organization; 2007.

21 Soldin OP. Controversies in urinary iodine determinations. Clin Biochem. 2002;35(8): 575-9.
22 Hollowell JG, Staehling NW, Hannon WH, Flanders DW, Gunter EW, Maberly GF, et al. Iodine nutrition in the United States. Trends and public health implications: iodine excretion data from National Health and nutrition examination surveys I and III (19711974 and 19881994). J Clin Endocrinol Metab. 1998; 83(10):3401-8.

23 Johner SA, Thamm M, Schmitz R, Remer T. Examination of iodine status in the german population: an example for methodological pitfalls of the current approach of iodine status assessment. Eur J Nutr. 2016;55(3):127582.

24 Konig F, Andersson M, Hotz K, Aeberli I, Zimmermann MB. Ten repeat collections for urinary iodine from spot samples or 24-hour samples are needed to reliably estimate individual iodine status in women. J Nutr. 2011; 141(11):2049-54.

25 Fukayama H, Nasu M, Murakami S, Sugawara M. Examination of antithyroid effects of smoking products in cultured thyroid follicles: only thiocyanate is a potent antithyroid agent. Acta Endocrinol. 1992;127(6):520-5.

26 Knudsen N, Bülow I, Laurberg P, Ovesen L, Perrild H, Jørgensen T. Association of tobacco smoking with goiter in a low-iodine-intake area. Arch Intern Med. 2002;162(4):439-43.

27 Vestergaard P. Smoking and thyroid disorders: a meta-analysis. Eur J Endocrinol. 2002; 146(2):153-61.

28 Åsvold BO, Bjøro T, Nilsen TIL, Vatten LJ. Tobacco smoking and thyroid function: a population-based study. Arch Intern Med. 2007;167(13):1428-32.

29 Elmadfa I. In: Elmafda I, editor. Österreichischer Ernährungsbericht 2012, 1. Auflage. Vienna: Druckerei Berger; 2012.

30 Rust $\mathrm{P}$, Hasenegger V, König J In: Rust P, Hasenegger V, König J, editors. Österreichischer Ernährungsbericht 2017. Vienna, Austria; 2017.
Oral Contraceptive Intake and Iodine Status
Ann Nutr Metab 2021:77:231-235 